Psychological Medicine, 1992, 22, 835-838. Copyright (C) 1992 Cambridge University Press

Printed in Great Britain

EDITORIAL

\title{
Post-mortem studies in affective disorder ${ }^{1}$
}

The historical precedent of research into Parkinson's disease where a key neuronal deficit was identified in post-mortem brain tissue leading directly to clinically effective therapy has naturally encouraged investigators of other neuropsychiatric disorders to pursue post-mortem research. However, it seems that there may be more problems than promise in pursuing post-mortem studies in affective disorders. The disadvantages of this strategy are many and obvious - patients rarely die during an episode of depression and if they do they may be unrepresentative of affective disorders in general and agonal status, post-mortem delay and drug therapy may complicate or invalidate any findings. Even if these difficulties are circumvented by the application of careful clinical criteria and the use of suitably matched controls questions remain - will any changes seen be meaningful in a complicated, variable disorder and what conclusions can be drawn from single observations in a dynamic condition?

There is, however, a growing body of evidence that post-mortem studies are useful adjuncts in affective disorder research provided that the limitations of this approach are appreciated. In fact, the post-mortem approaches may be vital to the testing of important hypotheses e.g. in depression in later life, in refractory affective disorders and in affective disorders associated with neuropsychiatric disease.

Many of the limitations and caveats outlined above were also applied to the post-mortem approach to the study of dementia 20 years ago. In dementia research some of these problems still remain (e.g. selection bias - cases dying in hospital are over-represented). Research has shown that many neurotransmitter-related activities such as metabolic enzymes, receptors and some metabolites are relatively stable post-mortem and not substantially affected by prolonged storage in freezers (Perry \& Perry, 1983). The wise investigator should, however, analyse all human data for effects of post-mortem delay and certainly match control and disease groups. Post-mortem stability can vary between normal and pathological groups as has been demonstrated for certain neuropeptides in dementia (Biggins et al. 1983). Age is another major factor to be considered since most transmitter activities vary as a function of age and the use of suitable age-matched controls is thus necessary. It is wise to avoid cases with prolonged anoxia and those who have been exposed to certain drugs, e.g. cytotoxics. Certain parameters (especially messenger RNAs) are particularly susceptible to the influence of agonal status as are some transmitter activities (e.g. the enzyme-synthesizing $\gamma$-amino butyric acid and the glycine modulation of the NMDA receptor (Perry \& Perry, 1983; Piggott et al. 1992). Post-mortem studies in dementia have revealed important associations between neuropathological changes, neurochemical abnormalities and clinical state ante-mortem. The relationship between senile plaques, cholinergic deficits and cognitive impairment in Alzheimer's disease (Perry, E. K. 1986) is an obvious example, but there are many more. The post-mortem neuropathological approach has in conjunction with clinical assessment facilitated delineation of sub-types of dementia - e.g. multi-infarct dementia, senile dementia of the Lewy body type (Perry et al. 1990). Post-mortem studies allow appropriate clinical criteria to be drawn up for these conditions which can then be examined in their more typical forms potentially leading to relevant clinical observations and hopefully rational therapy. Within Alzheimer's disease the post-mortem approach has led to the testing of important hypotheses (e.g. whether the neurochemical changes in the cortex are antegrade or retrograde in origin (Perry, R. H. 1986)) and the recognition of sub-

\footnotetext{
' Address for correspondence: Professor I. N. Ferrier, University of Newcastle-upon-Tyne, School of Neurosciences, Division of Psychiatry. The Royal Victoria Infirmary, Queen Victoria Road, Newcastle-upon-Tyne NEl 4LP.
} 
types of the disorder. Increasing attention is being paid to the non-cognitive symptoms of Alzheimer's disease, e.g. aggression, wandering, psychotic features, depression etc. (and many of these represent major burdens for carers) and the post-mortem approach may help the elucidation of the neurochemical basis of these syndromes leading to more targeted therapy. For example, does aggression relate to changes in the 5HT system and does apathy and withdrawal follow locus coeruleus pathology and noradrenergic deficits in frontal cortex (Zubenko et al. 1990)? Answers to these questions may soon be forthcoming and be a vital stage in the understanding of the role of these neuronal systems in disturbed behaviour.

Post-mortem studies in affective disorder have utilized either brains from suicide victims or from patients dying during an episode of depression either by suicide or by an intercurrent illness. The advantages of using suicide cases are that it is (unfortunately) relatively easy to collect material from younger subjects with no evidence of physical disorder and it is possible to exclude those who have taken drugs of all sorts more easily. However, preceding clinical information is often lacking and detailed mental states rare. The advantages of examining brains from out-patients or in-patients with an established affective disorder are that detailed histories are available and mental state records allow diagnostic criteria to be applied. However, such cases are rarer and are often complicated by drug therapy and, as many cases are elderly, intercurrent physical illness is often present. Detailed neuropathological investigation of this group is necessary to exclude the presence of neurodegenerative disease. An important, unresolved, question is whether the use of brains from both these groups will contribute useful information on the neurochemistry of affective disorder. The argument that the neurobiology of suicide differs significantly from that of major depression has to be considered. Attempts to overcome this problem have involved the inclusion of suicide cases where there is clearcut evidence of pre-existing depression. There is a need for studies comparing cases of suicide with and without preceding depression to attempt to resolve this issue. Important clues may be found in the neurochemical changes which are common to both depressed suicide victims and depressed cases dying of natural causes compared with those changes which do not appear to be shared between the two groups.

The serotonin (5HT) system has received most attention. Initial studies were inconclusive but there is now some consensus that post-synaptic $5 \mathrm{HT}_{2}$ receptors are increased in the middle cortical layers in both drug-free depressives and suicides (Yates et al. 1990; Arango et al. 1990) although there are contradictory reports (e.g. Cheetham et al. 1988). There is indirect evidence to support the hypothesis that $5 \mathrm{HT}_{1}$ receptors are functionally reduced in depression and that antidepressants (of all kinds) counter this abnormality (Deakin, 1989). However, no abnormality has been detected in cortical 5HT, receptors (and its subtypes) in depression (Ferrier et al. 1986; Yates \& Ferrier, 1990) or suicide cases (Cheetham et al. 1988) although reduced numbers of $5 \mathrm{HT}_{1}$ receptors have been found in the hippocampi of suicide victims (Cheetham et al. 1988). An autoradiographic study in the rat revealed that tricyclic antidepressants increase hippocampal $5 \mathrm{HT}_{1 \mathrm{~A}}$ receptors (Welner et al. 1989) and there is a need to apply this type of topographical technique to post-mortem brain of depressed patients, particularly to examine receptor distribution in discrete structures of the limbic lobe. There is much interest in the observation that all antidepressants down regulate $\beta$-adrenergic receptors and the suggestion that $\beta$-receptors may be altered in depressed brain. $\beta$-receptor numbers are increased in the frontal cortex of suicide victims (Arango et al. 1990) but not in brain tissue from depressed patients where no effect of antidepressants on $\beta$-receptors could be shown (Ferrier et al. 1986).

Corticotrophin-releasing factor (CRF) is a neuropeptide which functions as a neuromodulator and is involved in the mediation of stress responses. CRF is elevated in the CSF in depression (Nemeroff et al. 1984) and changes in CRF receptors have been found in suicide brain leading to the hypothesis that CRF is overactive in depression (Nemeroff et al. 1988). However, no changes were found in cortical CRF concentration in suicide brain or CRF receptors in frontal cortex from patients dying during an episode of depression (Charlton et al. 1988; Leake et al. 1990). This hypothesis needs to be pursued by examining the distribution of CRF in limbic areas of the brain (e.g. the hypothalamus and hippocampus). 
A potentially fruitful area for the post-mortem approach to affective disorders is the question of whether neurodegeneration may occur in major depression, particularly in later life when many systems of the brain have undergone a degree of natural age-related degeneration, potentially lowering functional safety margins. A significant number of elderly depressives have enlarged ventricles on computerized axial tomography and some of these cases also have evidence of cognitive impairment. The post-mortem approach is a valuable method of assessing changes in specific neuronal populations, including cell numbers and neurotransmitter receptors and metabolites with increasing age and some interesting trends are apparent (e.g. an inverted u-shaped curve for hippocampal cholinergic activity with age (Perry et al. 1992)). The depressive disorders seen in Parkinson's disease and Alzheimer's disease are associated with a greater reduction in 5HT turnover and fall in the number of 5HT neurones in the brain stem respectively (Mayeux et al. 1988; Zweig et al. 1988). It seems likely that exploring the relationship between changes in biological markers in diseases involving depression will pinpoint important mechanisms in the pathology of depression and that some forms of depression in later life may involve accelerated ageing. Only carefully conducted post-mortem studies with detailed clinical, neurochemical and neuropathological input can provide answers to questions like these. Another active hypothesis is that hippocampal degeneration may be involved in some forms of depression. In refractory bipolar disorder, temporal lobe EEG abnormalities (Levy et al. 1988) and reduced temporal lobe volumes using magnetic resonance imaging (Altshuler et al. 1991) have been reported. One possible mechanism for this is that the hippocampus has a high number of glucocorticoid receptors and elevated glutocorticoids may cause hippocampal degeneration (Sapolsky, 1987). One post-mortem study has reported smaller hippocampal volumes in suicide victims (Altshuler et al. 1990).

Hence post-mortem studies provide a useful tool in affective disorder research provided their limitations are understood and great clinical care is taken in the choice of material for study. Their continued value is a reflection on the major difficulties of interpreting psychopharmacological, neuroendocrine and imaging approaches to the study of affective disorder. The post-mortem approach should be seen as a method of indicating areas for further study. There are problems in measuring normally dynamic interactive neurotransmitter systems using a post-mortem approach and only single 'snapshots' of systems are examined. Results of post-mortem studies can indicate regions and neurotransmitters on which detailed imaging studies should be performed. It may be that post-mortem studies (with detailed neuropathology) of severe or atypical cases of depression will reveal important pathogenetic mechanisms and also delineate different forms and subtypes of depression, as has been the case for Parkinson's disease and dementia.

I. N. FERRIER AND E. K. PERRY

\section{REFERENCES}

Altshuler, L. L., Casanova, M. F., Goldberg, T. E. \& Kleinman, J. E. (1990). The hippocampus and parhippocampus in schizophrenic suicide and control brains. Archives of General Psychiatry 47, 10291034.

Altshuler, L. L.. Conrad, A., Hauser, P., Li, X., Guze, B. L., Deniskoff, K., Tourtelotte, W. \& Post, R. (1991). Reduction of temporal lobe volume in bipolar disorder: a preliminary report of magnetic resonance imaging. Archives of General Psychiary 48, 482483.

Arango, V., Ernsberger, P., Marzuk, P. M., Chen, J., Tierney, H., Stanley, M., Reis, D. J. \& Mann, J. J. (1990). Autoradiographic demonstration of increased serotonin $5-\mathrm{HT}_{2}$ and $\beta$-adrenergic receptor binding sites in the brains of suicide victims. Archives of General Psychiatry 47, 1038 -1047.

Biggins, J. A., Perry, E. K., McDermott, J. R., Smith, A. I., Perry, R. H. \& Edwardson, J. A. (1983). Postmortem levels of thyrotropic releasing hormone and neurotensin in the amygdala in Alzheimer's disease, schizophrenia and depression. Journal of Neurological Science 58, 117 . 122.

Charlton, B. G., Cheetham, S. C., Harton, R. W., Katona, C. L. E.,
Crompton, M. R. \& Ferrier, I. N. (1988). Corticotrophin-releasing factor immunoreactivity in post-mortem brain from depressed suicides. Journal of Psychopharmacology 2, 13-18.

Cheetham, S. C., Crompton, M. R., Katona, C. L. E. \& Horton, R. W. (1988). Brain 5- $\mathrm{HT}_{2}$ receptor binding sites in depressed suicide victims. Brain Research 443, 272-280.

Cheetham, S. C., Crompton, M. R., Katona, C. L. E. \& Horton, R. W. (1990). Brain 5-HT, binding sites in depressed suicides. Psychopharmacology 102, 544-548.

Deakin, J. F. W. (1989). SHT receptor subtypes in depression. In Behavioural Pharmacology of $5 H T$ (ed. T. Archer, P. Bevan and A. Cools), pp. 179-204. Laurence Erlbaum: New York.

Ferrier, I. N., McKeith, I. G., Cross, A. J., Perry, E. K., Candy, J. M. \& Perry, R. H. (1986). Postmortem neurochemical studies in depression. Annals of the New York Academy of Sciences 487, 128-142.

Leake, A., Perry, E. K., Perry, R. H., Fairbairn, A. F. \& Ferrier, I. N. (1990). Cortical concentrations of corticotrophin releasing factor and its receptor in Alzheimer-type dementia and major depression. Biological Psychiatry 28, 603-608. 
Levy, A. B., Drake, H. E. \& Shy, K. E. (1988). EEG evidence of epileptiform paroxysms in rapid cycling bipolar patients. Journal of Clinical Psychiatry 49, 232-234.

Mayeux, R., Stern, Y., Sano, M., Williams, B. W. \& Coté, L. J. (1988). The relationship of serotonin to depression in Parkinson's disease. Movement Disorders 3, 237-244.

Nemeroff, C. B., Widerlov, E., Bissette, G., Walleus, H., Karlsson, I., Ekland, K., Kitt, C. D., Loosen, P. T. \& Vale, W. (1984). Elevated concentrations of CSF corticotrophin-releasing factor-like immunoreactivity in depressed patients. Science 226, 1342-1344.

Nemeroff, C. B., Owens, M. J., Bissette, G., Andom, A. C. \& Stanley, M. (1988). Reduced corticotrophin-releasing factor binding sites in the frontal cortex of suicide victims. Archives of General Psychiatry 45, 577-579.

Perry, E. K. (1986). The cholinergic hypothesis - ten years on. British Medical Bulletin 42, 63-69.

Perry, E. K. \& Perry, R. H. (1983). Human brain neurochemistry: some postmortem problems. Life Sciences 33, 1733-1743.

Perry, E. K., Johnson, M., Kerwin, J. M., Piggott. M. A., Court, J. A., Ince, P. G., Shaw, P. \& Perry, R. H. (1992). Converging archicortical cholinergic activities in aging and Alzheimer's disease. Neurobiology of Aging (in the press)

Perry, R. H. (1986). Recent advances in neuropathology. British Medical Bulletin 42, 34-4l.

Perry, R. H., Irving, D., Blessed, G., Fairbairn, A. F. \& Perry, E. K.
(1990). Senile dementia of Lewy body type. A clinically and neuropathologically distinct form of Lewy body dementia in the elderly. Journal of the Neurological Sciences 95, 119139.

Piggott, M., Sahgal, A. \& Perry, E. K. (1992) Examination of parameters influencing $\left[{ }^{3} \mathrm{H}\right] \mathrm{MK} 801$ binding in postmortem human cortex. Journal of Neurochemistry 58, 10011009.

Sapolsky, R. M. (1987). Glucorticoids and hippocumpal damage. Trends in Neuroscience 10, 346349.

Welner, S. A., De Montigny, C., Desroches, J., Desjardins, P. \& Suranyi-Cadotte, B. E. (1989). Autoradiographic quantitation of serotonin $_{1 n}$ receptors in rat brain following antidepressant drug treatment. Synapse 4, 347352.

Yates, M. \& Ferrier, I. N. (1990). 5HT, receptors in major depression. Journal of Psychopharmacology 4, 69-74.

Yates, M., Leake, A., Candy, J. M., Fairbairn, A. F., McKeith, I, G. \& Ferrier, I. N. (1990). $5 \mathrm{HT}_{2}$ receptor changes in major depression. Biological Psychiatry 27, 489-496.

Zubenko, G. S., Moosy, J. \& Koop, U. (1990). Neurochemical correlates of major depression in primary dementia. Archives of neurology 47, 209-214.

Zwieg, R. M., Ross, C. A., Hedreen, J. C., Steele, C., Cordillo, J. E., Whitehouse, P. J., Folstein, M. A. \& Price, D. I.. (1988). The neuropathology of the aminergic nuclei in Alzheimer's disease. Annals of Neurology 24, 233242. 